\title{
Las tabernae de Pollentia (Mallorca). Materiales figurados como manifestaciones apotropaicas, de religiosidad, y de representación durante el siglo III
}

\section{Figurative materials in the tabernae of Pollentia: Apotropaic, religious, and trading manifestations during $3^{\text {rd }}$ century AD}

\author{
A. Santiago Moreno Pérez y Margarita Orfila Pons \\ Universidad de Granada
}

\begin{abstract}
RESUMEN
Se presentan una serie de materiales figurados recuperados en los niveles del siglo III d.C. en las tabernae estructuradas en insulae del entorno del foro de Pollentia. Estos materiales, principalmente esculturas exentas de pequeño formato, muestran distintas estrategias de representación y atracción de la clientela, pero también ciertas actitudes religiosas y supersticiosas, por lo que constituyen importantes indicadores sobre la vida cotidiana y el entramado de creencias de las clases populares que habitan estos establecimientos.
\end{abstract}

\section{SUMMARY}

A series of figurative materials found in commercial blocks around the forum of Pollentia in the 3rd century phase are herein presented. These materials, mainly small bronze sculptures, show different representation strategies and attraction of customers, but also certain religious and superstitious attitudes, and are therefore important indicators of the daily life and beliefs of the masses that inhabit these establishments.

PALABRAS CLAVES: Ínsulas comerciales romanas, escultura metálica, Pollentia, Mallorca.

KEY WORDS: Roman commercial blocks, metal sculpture, Pollentia, Mallorca.

\section{EL HÁBITAT DE LAS TABERNAE EN POLLEN- TIA}

Además de designar establecimientos donde se desarrollan transacciones comerciales y artesanales a pequeña escala ${ }^{1}$, el término taberna indicaba toda edificación susceptible de ser habitada ${ }^{2}$, caracterizada

\footnotetext{
${ }^{1}$ Digesto 50, 16, 185; Varro L. 8, 30, 55 .

${ }^{2}$ Digesto $50,16,183$. Para la discusión sobre la etimología
}

por su sistema de cierre en fachada ex tabulis ${ }^{3}$. Se trata, por tanto, de establecimientos donde se desarrollan actividades económicas y habitacionales de modo conjunto (Girri 1956; Gassner 1986; Pirson 1999), e indistintamente ligados a las clases populares, tal y como queda reflejado, en ocasiones en tono despectivo, desde la óptica de la élite urbana ${ }^{4}$. Del éxito de esta modalidad de vida urbana da cuenta su proliferación adoptando distintas estrategias de integración topográfica en las ciudades, llegando a cubrir grandes extensiones de la Urbs (Morel 1987; Purcell 1994) y, por extensión, de las aglomeraciones de entidad.

La ciudad portuaria de Pollentia reúne varias de estas estrategias de integración urbanística de las tabernae, documentándose: tabernae aisladas asociadas a insulae residenciales, como las detectadas en el barrio de Sa Portella (Arribas et alli 1978); asociadas a talleres artesanales de cierta envergadura (Arribas 1983: 39-40; Vallori et alii 2011: 294, fig. 10); y aglomeradas en insulae comerciales que circundan el área del foro de la ciudad. Estas últimas (Fig. 1) forman parte de las primeras actividades edilicias detectadas en la ciudad, entre los años 70-60 a.C. (Orfila et alii 1999: 104-108, 2005: 343-346, 2006; Orfila 2000: 139-40, 2007: 121-122; Cau y Chávez 2003; Vallori y Cau e.p.), incidiendo en la importancia del

de las tabernae en las fuentes literarias: MacMahon 2003; Monteix 2010: 42-48.

${ }^{3}$ Festo, Paul. 490, denominado clostrum por Séneca (Ben. $7,21,2)$.

${ }^{4}$ Por ejemplo: Livio 8, 20, 4; Plinio NH., 33, 49; Ciceron, Off. 1, 150. Sobre el tema: Purcell 1994; Papi 2002; MacMahon 2003. 


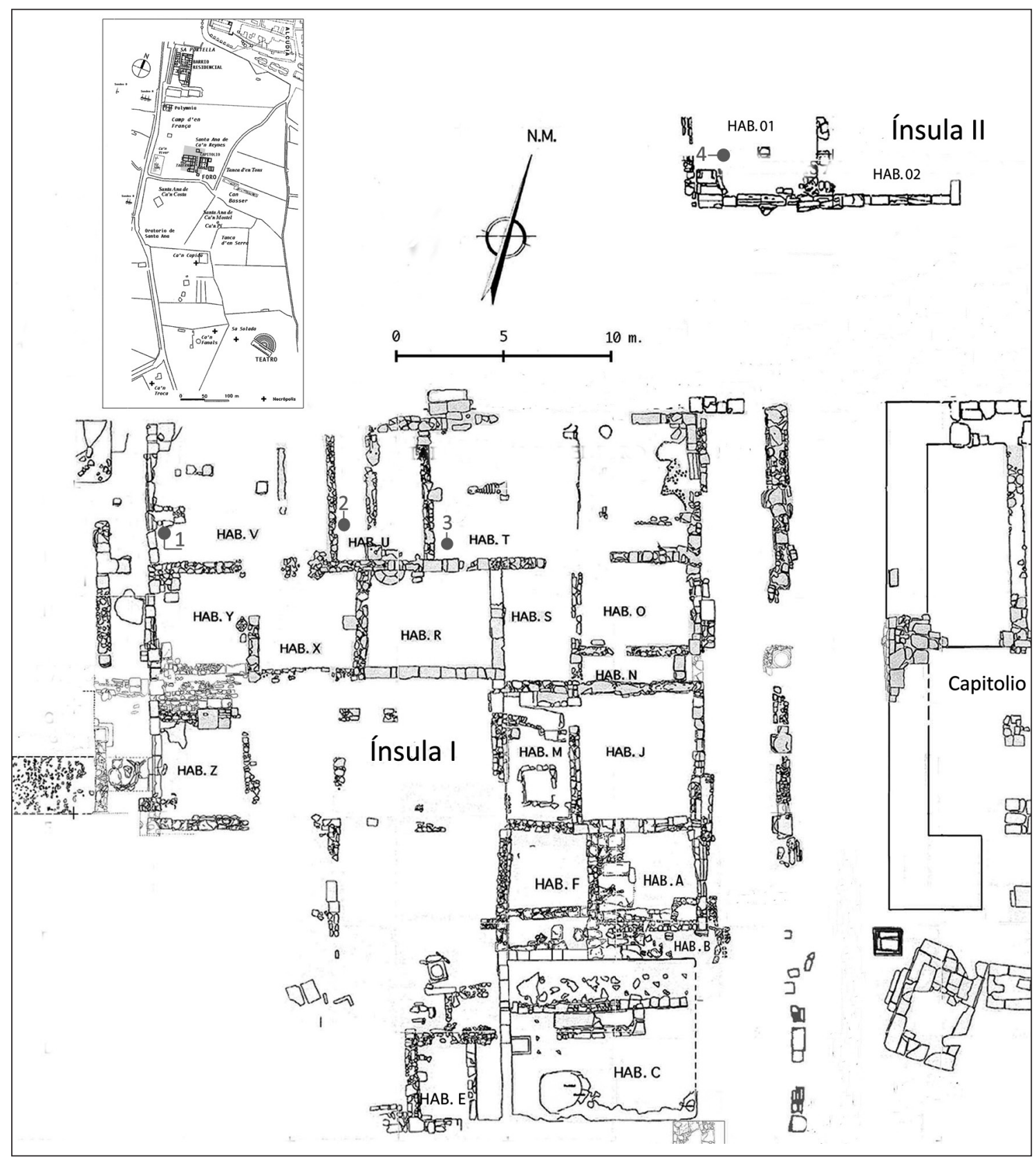

Figura 1. Las insulae entorno al Foro de Pollentia en el siglo III d.C. En la parte superior izquierda, topografía del yacimiento con situación (sombreada) de la zona analizada. Localización numerada de los objetos estudiados: 1. Estatuilla de Mercurio; 2. Caldero de plomo con relieves; 3.- Estatuilla de Baco; 4. Estatuilla de vaca.

carácter portuario y mercantil $1^{5}$, unido al estratégico y de control marítimo, en la iniciativa fundacional de la ciudad (Orfila 2000: 146, 2008: 18-19, 34), y

\footnotetext{
${ }^{5}$ La ciudad contó presumiblemente con dos puertos abiertos a las respectivas Bahías de Alcudia y Pollensa (Domingo et alii 2002; Orfila 2007: 114; Chávez et alii 2010).
}

constituyen, quizás junto con la ínsula junto al Foro de Ampurias (Balil 1972: 104-108), uno de los escasos ejemplos documentados de este tipo de aglomeración popular de Hispania.

A la época fundacional corresponde la Ínsula I, que cierra el foro por el oeste, la cual está ya pro- 


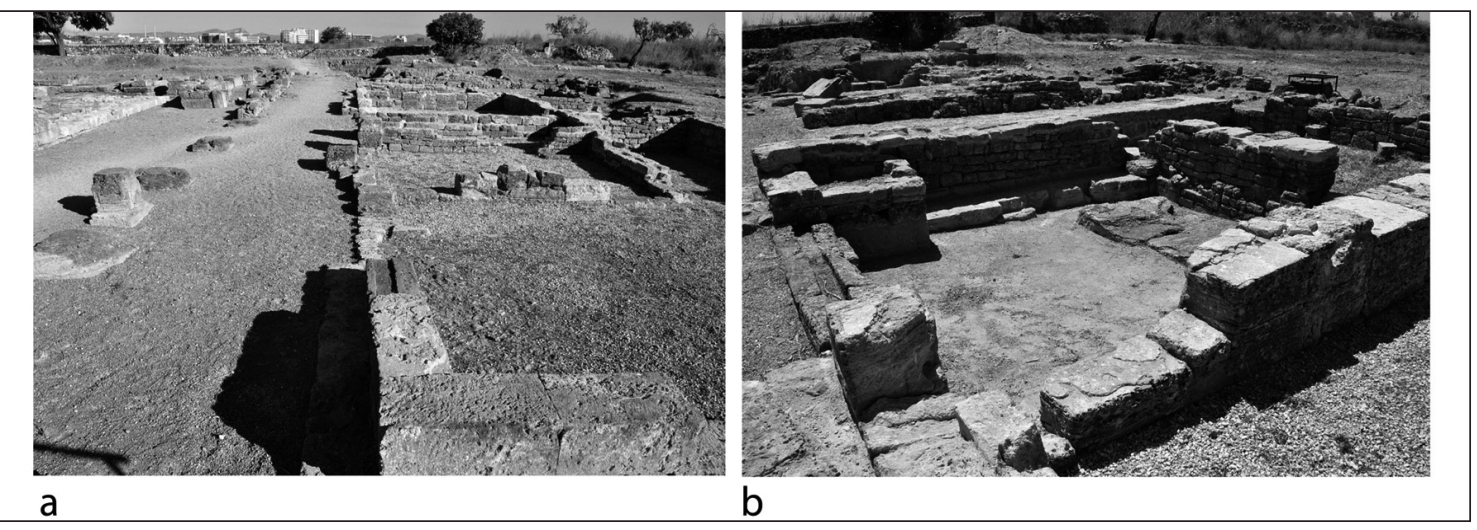

Figura 2. a) Vista del pórtico y las tabernae del lado este de la Ínsula I. b) La Habitación A, con pequeño mostrador de recepción y umbral con ranura para encajar el cierre de madera. Fotografías de S. Moreno.

vista de pórticos alineados a las fachadas (Fig. 2a), y se encuentra estructurada internamente por una serie de ámbitos rectangulares de distintos tamaños, organizados de modo predeterminado (Orfila 2000: 140, 2007: 121). En época imperial, a la vez que se llevan a cabo algunas modificaciones puntuales fruto del uso ininterrumpido de estos establecimientos, se edifica en el siglo II una posible nueva insula porticada, la Ínsula II, de la que se han excavado solo dos tabernae abiertas al decumanus que pasa por detrás del Capitolio (Equip d’Excavacions 1994a: 220; Orfila et alii. 1999: 110; Doengues 2005: 22). La edificación de estas nuevas tabernae cerrando el extremo norte del foro da cuenta del importante papel adquirido por el sector comercial en este periodo. A caballo entre finales del siglo II y el III se producen importantes transformaciones internas y externas en la Insula I, que queda entonces cerrada al foro mediante la creación de muros entre los intercolumnios de los pórticos, disponiéndose su acceso desde la calle que discurre al oeste de la insula. Estas transformaciones se mantuvieron operativas durante el siglo III hasta que un potente incendio fechado entre 270-80 d.C., detectado en distintas zonas de la ciudad, produjo el colapso de ambas insulae (Arribas y Tarradell 1987: 133; Equip d’Excavacions 1994b: 142; Orfila et alii 1999: 111, 2006). Es precisamente este periodo del siglo III, en el que se centra esta contribución, el mejor conocido desde el punto de vista arqueológico debido al abandono de estos complejos tras el mencionado incendio $^{6}$, y la preservación de estructuras y bienes muebles bajo los niveles de destrucción.

\footnotetext{
${ }^{6}$ Únicamente se han detectado puntuales indicios de ocupación en periodos posteriores, directamente asentados sobre los niveles de destrucción de la Ínsula I (Orfila 2000: 154).
}

Durante el siglo III la estructuración interna de la Ínsula I rompe con el diseño de época tardorrepublicana, imponiéndose una articulación heterogénea de los distintos establecimientos en cuanto a dimensiones, disposición en el interior de la ínsula, y número de estancias. Se detectan algunos ámbitos de mayor tamaño, compartimentados interiormente por tabiques (como la Habitación Q-T), y, principalmente, asociación de estancias, generalmente dos (Habitaciones J-M, A-F, Y-X, y O-S). Las principales, habitualmente más grandes, se encuentran abiertas a los pórticos de la calle ${ }^{7}$, y estaban reservadas al trabajo, venta y recepción de la clientela, tal como indica la presencia de mostradores (Fig. 2b), entre otros indicios. Las posteriores funcionaron de modo mixto como de trastiendas, hallándose depósitos de grandes contenedores como el de la Habitación X (Orfila et alli 1999: 112; Doengues 2005: 26-34), zona de trabajo, y, al igual que en otros centros urbanos, debieron albergar también funciones habitacionales (Girri 1956; Gassner 1986; Pirson 1999; MacMahon 2003; Mastrobattista y Santoro 2007; Santoro et alii 2011), como señalan los materiales vinculados a actividades domésticas ya desde el periodo tardorrepublicano (Orfila et alii 1999: 104).

Este complejo entramado de establecimientos debía estructurarse en torno a algún tipo de espacio abierto comunal ubicado en el interior de la insula (Orfila 2007: 122), la cual contó al menos con un piso superior al que se accedía por unos estrechos corredores (Habitaciones B, N, o el espacio entre Y y Z) abiertos directamente a los pórticos, donde se

\footnotetext{
${ }^{7}$ Es en estas aperturas en las que se han conservado los característicos umbrales de piedra con ranura longitudinal para el ensamblaje de los correspondientes tablones (Habitaciones A, J, V, Y, P, O, Z, y 01).
} 
instalaron probablemente escaleras de madera (Orfila et alii 1999: 112; 2005: 344; Vallori y Cau e.p.). La incomunicación de estos corredores con las distintas estancias del piso bajo de la ínsula plantea la posibilidad de que se trate de ambientes desligados de las tabernae, tal vez al modo de algunas insulae ostienses con tabernas en el piso bajo y apartamentos independientes en el superior (Girri 1956; Packer 1971). No obstante, no puede descartarse la presencia de altillos, o pergulae, en alguno de estos establecimientos, a los cuales pudieron dar acceso pequeños corredores detectados en el interior de algunas tiendas (Habitaciones $\mathrm{P}$ y V) donde posiblemente se instalarían escaleras de madera no preservadas (Doengues 2005: 19). La hipótesis se apoya también en la frecuente concurrencia de este tipo de estancias anexas en urbes como Ostia, Pompeya o Herculano ${ }^{8}$, las cuales están generalmente destinadas al descanso y actividades reservadas de los tabernarii (Mastrobattista y Santoro 2007; Mastrobattista 2009).

En definitiva el hábitat en estas tabernae pollentinas se ajusta al típico modelo de espacio doméstico reducido y supeditado al destinado a la actividad económica, el cual ocupa además las zonas mejor iluminadas y aireadas. Entre estas actividades económicas del siglo III, además de distintos artefactos relacionados con transacciones comerciales, se han identificado pequeños talleres artesanales, como la posible taberna vitraria / lignaria de la Habitación V (Orfila et alii. 1999: Doengues 2005: 34-38). Por otro lado, debieron ser frecuentes los comercios destinados a la venta de productos alimentarios preparados, una actividad específicamente documentada en el establecimiento conformado por las Habitaciones Y y X (Doengues 2005: 26-34), y que posiblemente estuviera presente en otras tabernae provistas de mostradores de obra a la entrada (Habitaciones Y, A, U, y 01 en la Ínsula II), habida cuenta de la recurrencia a este tipo de estructuras en negocios alimentarios (Monteix 2010: 63-68, 92-96).

\section{ELEMENTOS ORNAMENTALES DE REPRE- SENTACIÓN}

Quizás los elementos de representación más notables de las tabernae urbanas se dispusieron en sus fachadas mediante soportes pictóricos, tal y como se ha preservado de modo excepcional en Pompeya y Herculano. Estas pinturas de fachada, principalmente

\footnotetext{
${ }^{8}$ En la sección 3 "Aspectos religiosos", se incluye la figura $4 \mathrm{a}$, donde puede apreciarse un ejemplo de acceso interior mediante a escaleras a la pergula de una taberna.
}

orientadas a la atracción de la clientela, constituyen complejos mensajes iconográficos donde se mezclan ideas y asociaciones religiosas con referencias mercantiles y propagandísticas, conformando emblemas de alta significación para el conocimiento de la vida cotidiana de las clases populares (Clarke 2003: 75112; Mastrobattista y Santoro 2007: 117; Monteix 2010: 49-54). Lamentablemente en Pollentia no se han documentado este tipo de dispositivos iconográficos externos, por lo que los indicios disponibles se localizan en el interior de los establecimientos. Uno de los recursos básicos debió ser la decoración pictórica parietal y de mostradores en las estancias de recepción, ampliamente atestiguada en las ciudades vesubianas, pero del que restan únicamente fragmentos de estucos coloreados, como los de las Habitaciones U (Doengues 2005: 40-41), y E (Merino 1999: 44-45; Vallori et alii 2011: 290), estando especialmente constatados en las habitaciones de recepción de la pequeña officina alfarera excavada en el Sector Sur de la ciudad, donde se cita incluso decoración estucada en relieve con representación de parras (Llabrés e Isasi 1934: 10-18; Vallori et alii 2011: 294). Elementos excepcionales en este sentido son las pequeñas piezas de vidrio opaco con decoración incrustada de animales marinos (peces y pulpos) halladas tras los restos del mostrador de la Habitación $\mathrm{U}^{9}$, las cuales se integrarían en un panel parietal ornamental de alta calidad (Arribas y Doengues 1995: 409-412; Doengues 2005: 40), que pudo decorar las paredes, algún elemento mobiliario, o el propio mostrador. En este sentido, los mostradores del área vesubiana suelen ser importantes receptores de ornamentación pictórica, y en algunos casos de incrustación de placas de mármoles, encontrándose específicamente documentados distintos motivos faunísticos, entre ellos, por ejemplo, los peces de la caupona pompeyana de Pherusae (III, 6, 1. Monteix 2010: 95, fig. 33). En cualquier caso, el panel de la Habitación U constituye un dispositivo ornamental destacado, y posiblemente una referencia a los productos comerciados ${ }^{10}$, en este caso alimentos, hipótesis que avala igualmente la existencia de mostrador de obra en el local y el hallazgo, frente a este, de un caldero de plomo asociado a la cocción en tabernae de venta de alimentos y bebidas preparadas ${ }^{11}$.

\footnotetext{
${ }^{9} \mathrm{El}$ zócalo divisorio de la habitación, dispuesto directamente sobre el pavimento de tierra compactada del siglo III (Doengues 2005: 39, muro 117), debía ser la base del mostrador, generalmente dispuesto según este sistema sin cimentación (Monteix 2010: 93).

${ }^{10}$ La venta de productos preparados derivados del pescado, probablemente garum o salsamenta, está constatada en Pallentia (Equip d'Excavacions 1994a: 219), por ejemplo en el negocio conformado por las Habitaciones Y y X (Doengues 2005: 32).

${ }^{11}$ Los editores del artefacto (Arribas y Doengues 1995:
} 
Junto a este tipo de recursos de ornamentación de estructuras, en estos niveles del siglo III se han recuperado diversos artefactos decorados que inciden en este interés por la autorepresentación, y que sugieren cierta capacidad económica por parte de los tabernarii. Algunos de ellos reproducen temáticas báquicas, como el asa de bronce con decoración en relieve localizada entre las Habitaciones X e Y (Doengues 2005: 33, fig. 3.9), o el balsamario en forma de joven sátiro hallado frente al mostrador de la Habitación U (Arribas y Doengues 1995: 406-409). En ambos casos se trata de recipientes suntuarios en los que este tipo de temáticas presentan una orientación fundamentalmente ornamental (Manfrini 1987; Tassignon 1996: 129-134), y su empleo en estos establecimientos parece emular las tendencias decorativas de los contextos domésticos acomodados, en las que este tipo de motivos mitológicos gozaron de gran estima, tal y como se constata en la propia Pollentia (Moreno et alii 2011). Por otra parte, su presencia en estos locales pollentinos ${ }^{12}$, corresponde a una ambientación báquica firmemente atestiguada también en contextos populares y comerciales (Bakker 1994: 92-93; Santoro et alii 2011: 197), especialmente del área vesubiana, donde las imágenes de Baco son las segundas en importancia cuantitativa en los emblemas de fachada de tabernae (Monteix 2010: 52-53, fig. 17).

Una imagen en principio desprovista de carácter religioso, aunque compleja de interpretar desde una perspectiva funcional, es la pequeña estatuilla en bronce exenta de vaca $^{13}$ recuperada en el interior de la Habitación 01, en la Ínsula II (Fig. 3a). Vacas de estas características fueron empleadas como deco-

398-401) se decantan por la función de cofre, loculus, si bien estos elementos han sido recientemente analizados, identificándose su uso como calderos, generalmente insertados total o parcialmente en el mostrador de obra (Monteix 2010: 97-101). De la decoración de este artefacto se tratará en la sección 4 "Aspectos apotropaicos". Otro de estos calderos, actualmente sin localizar, se recuperó en las excavaciones del área del foro en 1926 (Ventayol 1927: 56, “...una caja de caudales de plomo deformada...").

${ }^{12}$ Debe tenerse en cuenta que las dos estancias están asociadas a posibles establecimientos alimentarios, y en el caso de las Habitaciones X-Y con ánforas vinarias documentadas (Doengues 2005: 48), un producto comercializado en la Ínsula I desde el período tardorrepublicano (Orfila et alii 1999: 104). No obstante, se trata de artefactos cuyas temáticas ornamentales resultan genéricas y comunes en distintos contextos privados, por lo que no puede establecerse con garantías su relación directa con la comercialización de vino. Más bien, como argumentábamos atrás, se trataría de recursos ornamentales de representación.

${ }^{13} \mathrm{Su}$ editor (Doengues 2005: 22, fig. 2.7) la identifica con un toro. La estatuilla tiene claramente representadas las ubres. Fundición plena a la cera perdida, $4,4 \mathrm{~cm}$ de altura x $6,4 \mathrm{~cm}$ de longitud, se conserva en el Museo de Mallorca, $\mathrm{n}^{\circ}$ de inv. CE08/07/001. ración del mobiliario, al modo del aplique (Fig. 3b) fijado al brasero de las Termas del Foro de Pompeya (Eschebach 1991: 269, figs. 34 y 35), o por ejemplo en relieves funerarios de temática bucólica, entre los que se encuentran vacas estilísticamente muy próximas a la pollentina fechadas en la segunda mitad del siglo III y comienzos del IV (Papini 2000: 267-268). Ambos ejemplos avalan el uso simbólico/ornamental de imágenes de vacas.

Por otra parte, relieves zoomorfos relativos a la naturaleza de los negocios se han documentado por

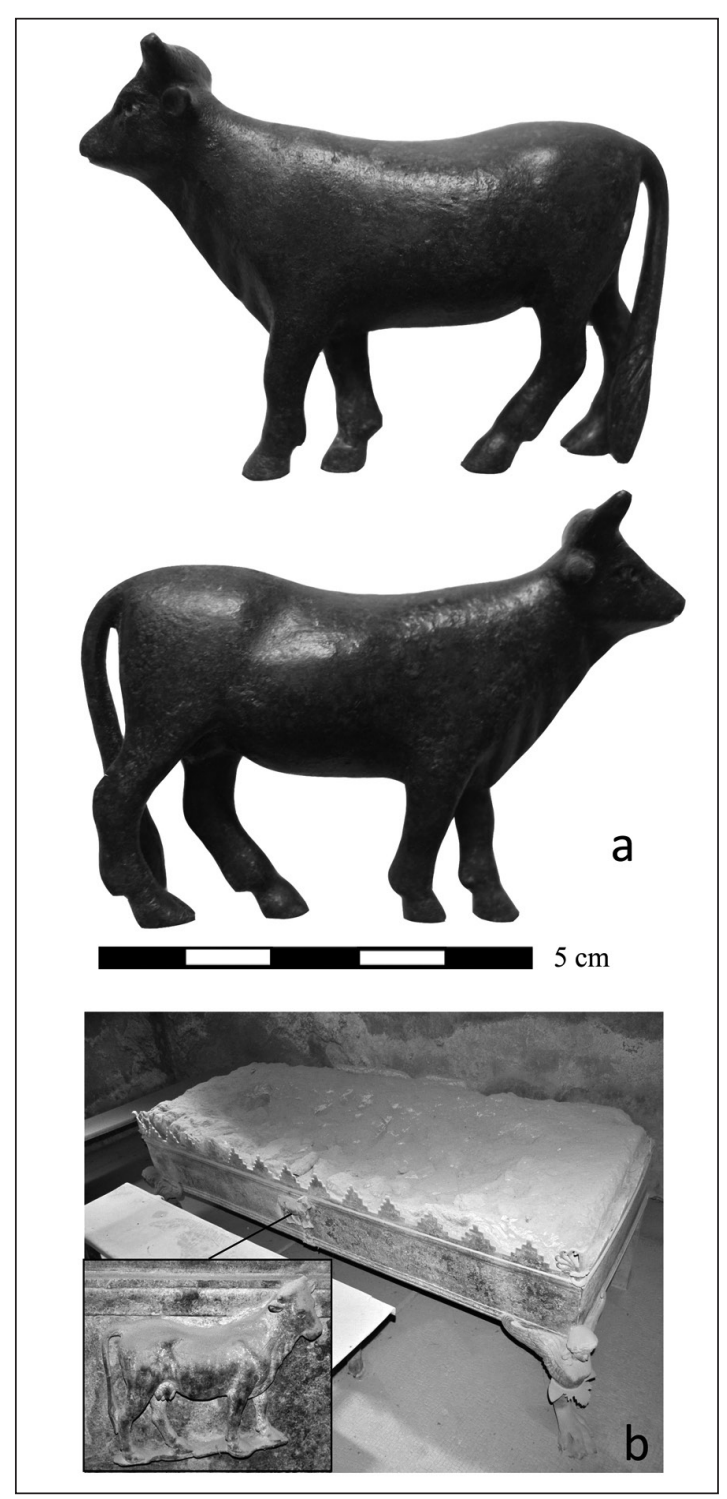

Figura 3. a) Vaca recuperada en los niveles del siglo III de la Habitación 01 (Ínsula II). b) Brasero in situ de las Termas del Foro de Pompeya. Fotografías de S. Moreno. 
ejemplo en Pompeya (Avvisati 2007: 98, fig. 48), y observaciones similares se han planteado a propósito de una cabeza de bóvido esculpida en la fachada de una de las tabernae de Mirobriga, en Lusitania (Barata 1994), por lo que tampoco pueden descartarse definitivamente una posible referencia a los productos comercializados, cuestión que se apoyaría en la destinación alimentaria de la Habitación 01 en base a la presencia de mostrador y de restos de dolia (Orfila et alii. 1999: 112; Doengues 2005: 22; Orfila 2007: 123). Sin embargo, el formato de la pieza, exenta y con la base de las patas planas para soldar a una pequeña base o pedestal, resulta más propio de estatuillas de larario, una situación que cuenta con paralelos como el del conjunto de Sibari (Kaufmann-Heinimann 1998: 299), donde entre una serie de divinidades aparece una vaca exenta de bronce sobre pedestal amamantando a un ternero. De ser este el caso, la imagen pudo asumir un carácter simbólico o apotropaico ${ }^{14}$ más que religioso en un posible larario no conservado, cuestión que no atenuaría su valor ornamental y como recurso de autorepresentación en la estancia de recepción de la taberna 01 .

\section{ASPECTOS RELIGIOSOS}

Los límites entre los elementos pertenecientes a los recursos ornamentales de representación de las tabernae y los relativos a los cultos religiosos practicados por sus habitantes son, en ocasiones, difíciles de precisar, tal como se ha comentado a propósito de las temáticas de fachada, donde con frecuencia religión, representación, y atracción de la clientela aparecen mezclados como parte de un mensaje iconográfico complejo. En este sentido, los sacra privata se evidencian mediante la existencia de estructuras cultuales, singularmente lararia de distintas tipologías, o de bienes muebles asociables a estas, tales como pinturas, estatuillas o pequeños altares ${ }^{15}$. No obstante, los lararios instalados en las zonas de recepción de la clientela no estuvieron tampoco exentos de cierto sentido de autorepresentación religiosa (Orr 1978: 1579; Santoro et alii 2011), y hay que tener en cuenta que en esta situación se encuentran 48 de

\footnotetext{
${ }^{14}$ Las representaciones de bóvidos con carácter apotropaico son frecuentes, y están documentadas en el caldero de plomo de la Habitación U, sobre el que se volverá más adelante. En el larario de Sibari mencionado se incluyó también una estatuilla de toro exenta que probablemente tuvo un significado de protección.

${ }^{15}$ Otro tipo de actividades religiosas, que no vamos a tratar aquí por falta de evidencias en Pollentia, son los depósitos votivos en fosas fundacionales de tabernae, detectadas tanto en Italia como en la Península Ibérica (Pérez Asensio 2007).
}

78 lararios pompeyanos en ambientes comerciales y artesanales (Fig. 4), la mayoría de tipo nicho parietal simple (Santoro et alii 2011: 187-188).

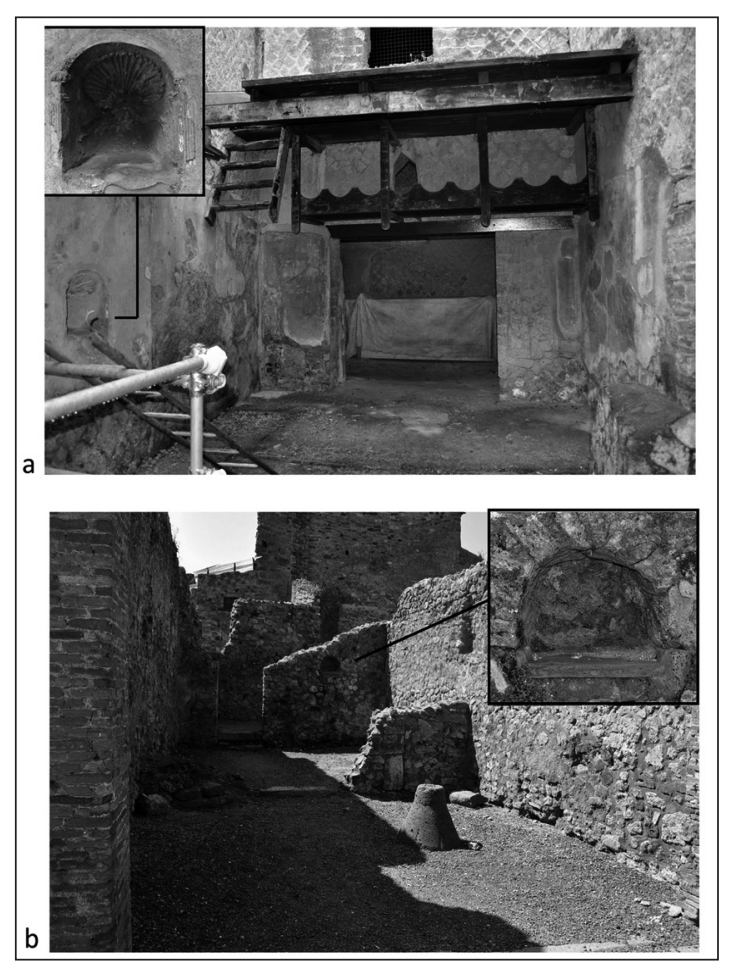

Figura 4. a) Taberna vinaria de Herculano (Or. II, 9), con larario en la habitación de recepción. Nótese la presencia de parte de las escaleras de madera que dan acceso a la pergula del local. b) Taberna pompeyana (VI, 8, 15) con larario en trastienda. Fotografías de S. Moreno.

La deficiente conservación de los alzados arquitectónicos de las tabernae pollentinas ha impedido identificar este tipo de estructuras cultuales, cuyo uso en tabernae y pequeños centros artesanales debió ser frecuente tanto en Italia como en las provincias occidentales (Santrot 1993; Bakker 1994: 183-184; Santoro et alii 2011: 190-198). No obstante, es posible plantear su existencia durante el siglo III en función del hallazgo de estatuillas de divinidades típicas de larario (Orfila 2007: 123), cuya función en la liturgia privada tuvo un carácter fundamentalmente vehicular en el proceso de invocación y propiciación de las divinidades ${ }^{16}$, y que permiten identificar ciertas tendencias religiosas entre los comerciantes pollentinos.

Una de estas tendencias, la del culto a Baco, formó parte también, como se ha señalado, del aparato orna-

${ }^{16}$ Sobre el tratamiento litúrgico de la estatuaria de culto: Weddle 2010. 


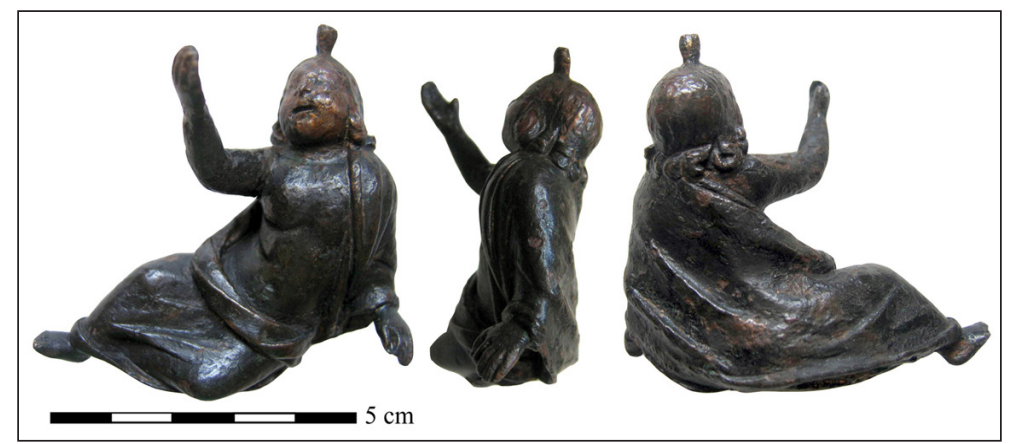

Figura 5. Estatuilla de Baco procedente de los niveles del siglo III de la Habitación T. Fotografías de S. Moreno.

mental de representación en los ambientes comerciales de la ciudad, si bien las circunstancias del hallazgo de una estatuilla exenta del dios, así como su formato, plantean su empleo como divinidad protectora del establecimiento integrado por las Habitaciones Q y $\mathrm{T}$ y sus habitantes ${ }^{17}$. La estatua de bronce (Fig. 5) ${ }^{18}$ se recuperó sobre el pavimento del extremo suroeste de la estancia $\mathrm{T}$, una trastienda o zona de trabajo independizada de la Habitación Q (esta última abierta a la calle) en las reformas de comienzos del siglo III (Doengues 2005: 42-45), por lo que se trata de un ambiente privado, desligado de funciones de recepción de clientela. El tipo de Baco adolescente, recostado en posición de banquete, y cubierto parcialmente por un amplio manto se atestigua en época imperial en episodios mitológicos como el concurso de bebida, la hierogamia de Baco y Ariadna, y el triunfo de Baco, aunque generalmente en soportes glípticos, mosaicos y relieves sarcofágicos a partir del siglo II d.C. (Gasparri 1986: 555-556), sin que se hayan localizado reproducciones en pequeños bronces ${ }^{19}$. Por el contrario, el formato y posición recostada de la estatua se encuadra en una serie de bronces de larario con representaciones exentas de divinidades, como Fortuna (Ortego 1949) o Mercurio (Galliazzo 1979: 72-73), y genios familiares (Kunckel 1974: 94 y 96), todas ellas fre-

\footnotetext{
${ }^{17} \mathrm{El}$ establecimiento presenta importantes zonas perturbadas por las excavaciones de los años 20, por lo que su delimitación respecto a la Habitación $\mathrm{P}$ no ha quedado del todo clara. Así mismo, cuenta con un acceso a la Habitación R, la cual parece también conectada con la U (Orfila et alii 1999: 104; Doengues 2005: 42-44), quizás una trastienda o estancia compartida por ambos establecimientos.

${ }^{18}$ Publicada inicialmente por N. Doengues (225: 45, fig. 3.17 ), tiene $5,7 \mathrm{~cm}$ de altura $x 6,1 \mathrm{~cm}$ de anchura. Fundición pena a la cera perdida. Se conserva en el Museo de Mallorca, $\mathrm{n}^{\circ}$ de inv. CE08/07/005.

19 Únicamente algunas imágenes infantiles del dios recostado y desnudo, de concepción muy distinta al pollentino (Manfrini 1987: 136-137, fig. 280).
}

cuentes entidades tutelares de los cultos domésticos. Estas estatuillas están fundidas junto con los lechos que sirven de base de apoyo, un elemento que con probabilidad se fundió por separado en el ejemplar mallorquín, para ser ensamblado en la cavidad de unos $0,3 \mathrm{~cm}$ que conserva en la base ${ }^{20}$, avalando el carácter exento de la pieza, y su posible inserción en un larario no conservado en esta Habitación $\mathrm{T}^{21}$.

En efecto, el culto de Baco en soportes pictóricos sobre lararia está documentado en el área vesubiana principalmente en tabernae, y escasamente en los lararios de contextos domésticos acomodados, tratándose de una divinidad venerada fundamentalmente por las clases subalternas y comerciantes (Orr 1978: 1581; Adamo-Muscettola 1984: 11; Frölich 1991). Entre diversos ejemplos, resulta ilustrativo el del larario de la taberna vinaria Or, II, 9 de Herculano (Fig. 4a), de época flavia, centrado por la representación pictórica, hoy prácticamente perdida, de Baco envuelto con amplio manto, rodeado de Mercurio y Hércules (Frölich 1991: 302-303; Marchetti 200910: 52-54). Como práctica menos documentada, se recurrió también al empleo de estatuillas broncíneas, como la del larario del thermopolium V, 10 de Herculano (Marchetti 2009-10: 68-69). Baco, al igual que otras divinidades tutelares de la casa y la familia romana, adquiere posiblemente en estos contextos las atribuciones de los antiguos dioses Penates, particularmente en cuanto a su relación con la protección

\footnotetext{
${ }^{20}$ El brazo izquierdo, que se encuentra elevado, se apoyaría en este elemento perdido. Se desconoce si el brazo opuesto alzado y con la mano abierta sostenía algún atributo, tal vez una pátera como los genios familiares atrás citados. La Fortuna recostada de Soria lleva en esta mano el timón fundido por separado.

${ }^{21}$ Es curioso que en la fase inmediatamente anterior de la estancia se documentó una tegula en la esquina SW interpretada como posible base de un altar o mesa (Doengues 2005: 44, fig. 3.15).
} 
de los medios de subsistencia familiares (Pérez Ruiz 2007-2008: 205-207, 2014).

Actualmente resulta escasamente conocido el grado de recepción del culto báquico en ambientes comerciales de las provincias occidentales, si bien casos como el de las pinturas báquicas de la sede de una asociación artesanal de la aglomeración secundaria de Schwarzenacker (Santoro et alii 2011: 197-198), en las provincias transalpinas, nos recuerda la relación del dios con estos sectores sociales. En Hispania, además del caso pollentino, se puede citar el aplique de bronce con representación de cabeza de Baco hallado en la tienda B3 del macellum de Baelo Claudia, procedente de un nivel de los siglos III-IV d.C. (Sillieres y Didierjean 1977: 521-522, pl. 23), aunque se trata de un elemento de decoración de mobiliario que puede reflejar aspectos de autorepresentación más que propiamente cultuales.

Mucho más generalizado en ambientes comerciales fue la presencia de Mercurio, cuya tutela oficial de las actividades mercantiles dio paso, a partir del siglo II a.C., a su difusión privada como numen dispensador de lucro y prosperidad económica, fuertemente enraizado también en los sectores populares de la población (Combet-Farnoux 1980: 256-257, 406-411). Su presencia en las tabernae de Pollentia durante el siglo III está confirmada mediante el hallazgo de una estatuilla de bronce en la Habitación V, sin que pueda confirmarse si las otras dos estatuillas del dios recuperadas en las excavaciones de los años veinte en el área del foro se emplearon en estos contextos ${ }^{22}$. En cualquier caso, de su importancia en las tabernae pollentinas da cuenta el anillo sello procedente de los niveles del siglo III de la Habitación U, que lleva un caduceus, el atributo oficializado del dios (CombetFarnoux 1980: 426-428), bajo la inscripción ACTIACI, y que se ha relacionado con el sellado de productos perecederos (Arribas y Doengues 1995: 403-406).

El hallazgo de la estatuilla, en una taberna destinada en este periodo a distintas actividades artesanales a pequeña escala, se produjo tras el umbral del establecimiento, en las proximidades de los restos de una estructura, posiblemente una plataforma para el trabajo o mostrador (Doengues 2005: 37), por lo tanto en una zona de recepción de clientela. La estatua, de reducidísimas dimensiones (Fig. 6) ${ }^{23}$, se adscribe a una tipología muy frecuente y de amplia difusión geográfica, conocida como de clámide enrollada en

22 Sobre las estatuas: Pozo 1989: 70-72. Sobre las excavaciones de los años veinte en la zona del foro, incluyendo distintos puntos de la Ínsula I: Vallori et alii 2011.

${ }^{23}$ Doengues 2005: 37, fig. 3.11. 6,3 cm de altura x 2,7 de anchura. Fundición plena a la cera perdida. Se conserva en el Museo de Mallorca, $\mathrm{n}^{\circ}$ de inv. 28094.

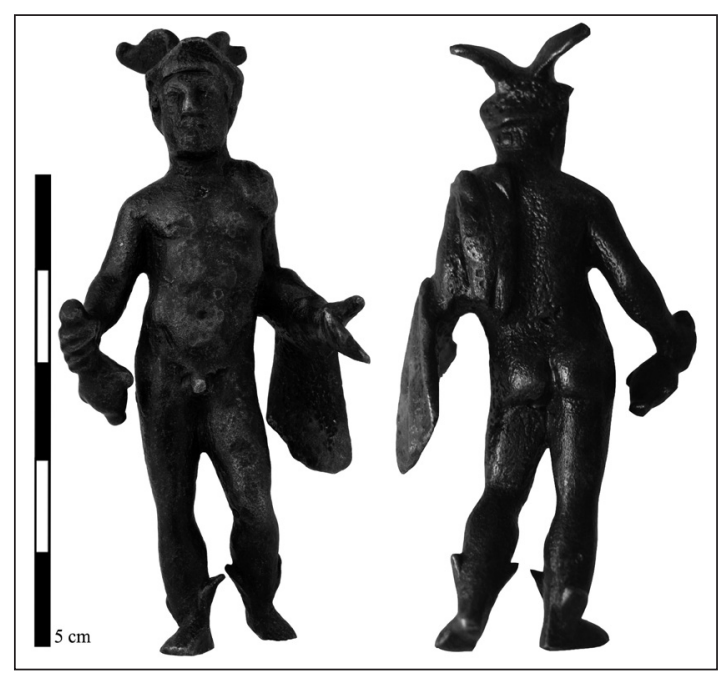

Figura 6. Estatuilla de Mercurio recuperada en los niveles del siglo III de la Habitación V. Fotografías de S. Moreno.

el brazo izquierdo ${ }^{24}$, si bien destaca su extremada similitud técnica y estilística con un ejemplar de la región parmesana (D’Andria 1970: 106, n 166), con el que comparte idénticas dimensiones e incluso el tipo de superficie porosa producida durante su fundición, por lo que es probable que se trate de producciones de Italia Septentrional. Su destinación cultual, posiblemente como dios Penate del establecimiento, se identifica por su carácter exento, con la base de los pies plana para soldar a un pequeño pedestal, sus dimensiones, y su bajo perfil suntuario debido a su concepción cualitativa limitada, todo lo cual avala su instalación en un posible larario no conservado, que pudo emplazarse en las inmediaciones del mostrador de recepción de la Habitación V.

Mercurio es, con diferencia, la divinidad más representada en dispositivos iconográficos de representación de tabernae vesubianas, presentándose en el $46 \%$ de los emblemas de fachada documentados en Pompeya y Herculano (Monteix 2010: 52, fig. 17), al tiempo que es también una de las más frecuentes en los lararios de los comerciantes, generalmente en soportes pictóricos (Orr 1978: 1581; Frölich 1991). Menos frecuente debió ser su presencia en forma de pequeños bronces, aunque se citan al menos uno en el larario del thermopolium pompeyano $\mathrm{V}, 1,13$ (Boyce 1937: 32, $\mathrm{n}^{\circ}$ 37), otro en una taberna sin larario de la Región VII (Boyce 1937: 108-109, nº

\footnotetext{
${ }^{24}$ Tipo 22 de E. Poulsen (1977). En Baleares es el único caso, estando mejor representada la variante de clámide triangular, al modo de los dos ejemplares ya mencionados de Pollentia y el único conocido en Menorca (Moreno 2012: 186).
} 
6), un ejemplar de Ostia posiblemente asociado a un local del Caseggiato dei Molini (Bakker 1994: 97), y un caduceus de bronce se localizó en un taller de orfebrería del siglo iII de Rotomagus, Galia (Lequoy y Guillot 2004: 129-131).

\section{ASPECTOS APOTROPAICOS}

Más allá de los beneficios derivados de la ejecución de determinadas prácticas religiosas, los establecimientos comerciales y artesanales se dotaron de una serie de iconos provistos, en la cosmovisión de la época, de propiedades apotropaicas, especialmente vinculadas a la protección contra el mal de ojo (Monteix 2010: 53-56). El elemento de este tipo que con mayores garantías se asocia a las tabernae de Pollentia son los relieves figurativos dispuestos en el ya mencionado caldero de plomo de la Habitación $\mathrm{U}^{25}$, con representaciones de un bóvido sobre plinto (por tanto una estatua de bóvido) y una cabeza de Medusa (Fig. 7).

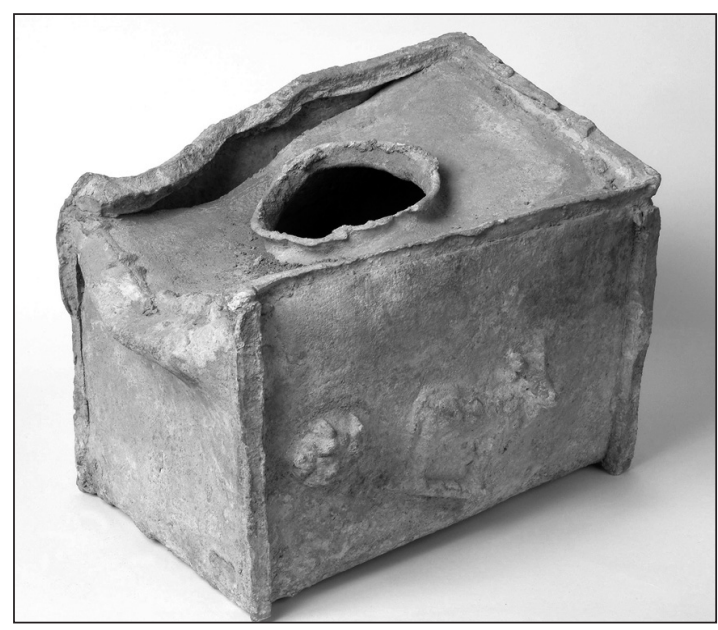

Figura 7. Caldero de plomo de los niveles del siglo III de la Habitación U. Foto: AAVV 2005: 80.

El motivo del bóvido astado aparece involucrado en algunas imágenes específicamente destinadas a la protección contra el mal de ojo (Alvar 2010: 179-180) y en algunos amuletos fálicos (De Caro 2000: 80, 86), mientras los gorgoneia poseían un carácter apotropaico integral, vinculado tanto a la protección en vida como en la muerte (Howe 1954). El uso profiláctico de gorgoneia queda evidenciado en ambientes comerciales en las estructuras de recepción,

\footnotetext{
${ }^{25}$ Ver nota $^{\circ} 11$
}

caso del mostrador de la taberna pompeyana I, 8, 1 (Monteix 2010: 96); en la decoración del mobiliario, como el aplique (picaporte) del taller de orfebrería de Rotomagus que citábamos atrás (Lequoy y Guillot 2004: 129-131); e incluso en instrumental específico de pesajes, caso de una báscula de la zona de Trento (Walde-Psener 1983: 92). Los editores del recipiente pollentino (Arribas y Doengues 1995), citan otro ejemplar en el Museo de Vienne que porta igualmente en relieve una cabeza de Medusa, además de dos leones saltando desde ambos lados, curiosamente un motivo específicamente constatado en el mostrador pompeyano del thermopolium I, 7, 14, en torno a una representación protectora de Príapo (Mastrobattista y Santoro 2007: 116-117; Monteix 2010: 96). Estos factores indican la aplicación de elementos apotropaicos en algunos de estos calderos de plomo ${ }^{26}$, conocidos también en ambientes domésticos, pero principalmente documentados en comercios alimentarios (Monteix 2010: 97-101).

Por otra parte, es posible plantear la asociación hipotética a estos establecimientos de alguno de los bronces de connotaciones profilácticas recuperados en la zona del foro durante las excavaciones de los años veinte $^{27}$. En concreto interesan dos ejemplares, que al igual que las estatuillas empleadas en las tabernae presentan reducidas dimensiones, recursos cualitativos limitados, y, al menos en uno de los casos, una temática de inspiración popular.

Uno de ellos es un carnero de bronce exento (Fig. 8b ${ }^{28}$, un animal de connotaciones simbólicas benéficas (Moreno 2012: 185), a las que se suma en este caso una caracterización fálica acusada, lo que constituye una asociación relativa a la protección contra el mal de ojo (Johns 1982: 68-70). De hecho, carneros itifálicos son elementos iconográficos destacados de algunos tintinabula (Jonhs 1982, fig. 54; Zampieri y Lavarone 2000: 120, $\mathrm{n}^{\mathrm{o}} 156$ ), y amuletos fálicos (Faider-Feytmans 1957: 105, nº 243), si bien el carácter exento del bronce mallorquín, con la base de las patas planas para soldar a pedestal, induce a considerarlo un elemento apotropaico posiblemente de larario. La otra pieza es una conocida estatuilla de bronce (Fig. 8a), también exenta y de reducida

${ }^{26}$ La mayoría no presentan decoración alguna, caso, seguramente, del ejemplar recuperado en las excavaciones del área del foro en 1926 (Ventayol 1927: 56). Esta pieza no se ha podido localizar.

27 Como se ha señalado, estas excavaciones afectaron también a la Ínsula I y su entorno (Vallori et alii. 2011). La relación más completa de las estatuillas recuperadas en las campañas de 1923 y 1926 figura en: Ventayol 1927: 53-56.

${ }^{28}$ La pieza, conservada en el MAN con el $n^{\circ}$ de inventario 33148 , carece de estudio específico. Tiene $4,8 \mathrm{~cm}$ de altura $\mathrm{x}$ $5,3 \mathrm{~cm}$ de longitud, fundición plena a la cera perdida. 


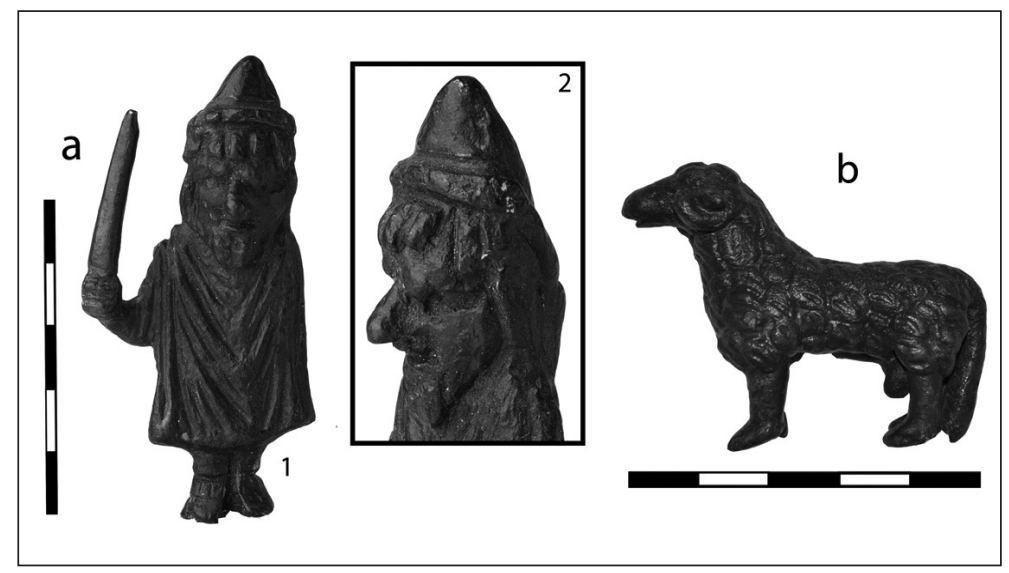

Figura 8. Estatuillas exentas recuperadas en el área del foro en 1926. a) Genio encapuchado. Fotografías: a1, MAN-33145-ID001; a2, MAN-33145-ID007. b) Carnero itifálico. Fotografía de S. Moreno.

talla (7 cm de altura), ya asociada por S. Perea con genios benéficos de posibles atribuciones mágicas o supersticiosas, y de carácter popular (Perea 1997) ${ }^{29}$, por lo que es probable su vinculación con las tabernae del área del foro. A las observaciones realizadas por este investigador quisiéramos añadir algunos aspectos que refuerzan la idea de su función profiláctica, seguramente en relación al mal de ojo. En primer lugar, la propia anatomía en relación al enanismo y rasgos faciales, que se encuadran en las figuraciones grotescas de carácter apotropaico (Alvar 2010: 207-224); la presencia de tirabuzones propios de representaciones de negroides o etíopes, personajes igualmente provistos de atribuciones protectoras (Clarke 2007); y las insinuaciones fálicas emitidas por la forma de la nariz, elemento que ya llamó la atención de sus excavadores $^{30}$. En efecto, en el ámbito de las imágenes grotescas se documenta la sustitución de determinados elementos anatómicos por representaciones fálicas ${ }^{31}$, cuestión que afecta también a determinadas representaciones de genios y demonios encapuchados caracterizados de modo falo-céfalo (Deonna 1955).

\section{CONCLUSIÓN}

La documentación expuesta en las secciones precedentes, muestra como estas insulae comerciales entorno al área forense se dotaron en el siglo III d.n.e.

\footnotetext{
${ }^{29}$ La pieza había sido interpretada con anterioridad como Genio mitraico (Pozo 1989: 73).

30 “...con nariz y barba disforme..." (Ventayol 1927: 55).

31 Por ejemplo, la nariz fálica de un centauro en relieve apotropaico, específicamente destinado a combatir el mal de ojo, de Leptis Magna (Johns 1982: 92, fig. 77).
}

de todo un "ecosistema" de imágenes orientado por una parte a la representación externa de las tabernae y sus habitantes, cuestión que revierte en la atracción de clientela y aumento de competitividad de los negocios, pero también relacionadas con la protección supersticiosa y determinadas prácticas religiosas. En el ambiente iconográfico, así como en las divinidades documentadas, se aprecian prácticas similares a las desarrolladas en Italia, bien sea en el área vesubiana o en aglomeraciones como Ostia, sin indicios de tendencias regionales como sucede, por ejemplo, en Galia, donde existió una especial veneración de Venus en contextos artesanales y comerciales (Talvas 2007: 286-288). Sin embargo, a diferencia de Pompeya o Herculano, donde este tipo de documentación es principalmente pictórica y perteneciente al siglo I d.n.e., llama la atención la concentración de elementos iconográficos en soportes metálicos, especialmente estatuillas exentas, en las tabernae pollentinas del siglo III. Ello se debe, al menos en parte, a la proliferación de este tipo de materiales que se detecta en Pollentia sobre todo a partir del siglo II d.n.e. (Moreno 2013), los cuales adoptaron las suficientes oscilaciones cualitativas como para permitir su recepción en diferentes estratos sociales.

\section{BIBLIOGRAFÍA}

AA.VV 2005: El mundo romano en las Illes Balears, catálogo de la exposición, Barcelona.

Adamo-Muscettola, S. 1984: "Observazioni sulla composizione dei larari con statuette in bronzo di Pompei ed Hercolano", U. Gehrig (ed.), Toreutik und Figürliche Bronzen römischer Zeit, Akten der 
6. Tagung uber Antiken Bronzen (Berlín, 1980), Berlin, 9-32.

Alvar, A. 2010: El mal de ojo en el occidente romano: materiales de Italia, Norte de África, Península Ibérica y Galia, tesis doctoral, Universidad Complutense de Madrid.

Arribas, A. 1983: "Pollentia: problemas de topografía y conservación de la ciudad", Pollentia y la romanización de las Baleares, Symposium de arqueología, XXI Centenario de la fundación de Pollentia (Alcudia 1977), Alcudia, 35-46.

Arribas, A., Tarradell, M. y Woods, D. 1978: Pollentia II. Excavaciones en Sa Portella. Alcudia (Mallorca), Excavaciones Arqueológicas en España 98, Madrid.

Arribas, A. y Tarradell, M. 1987: "El foro de Pollentia. Noticia de las primera investigaciones", Los foros romanos de las Provincias Occidentales, Ministerio de Cultura, Madrid, 121-136.

Arribas, A. y Doengues, N. 1995: "Piezas singulares de una estancia del área comercial del foro de Pollentia”, Actas del Primer Congreso de Arqueología Peninsular, Trabalhos de Antropología e Etnologia 35-1, Oporto, 397-420.

Avvisati, C. 2007: Pompei. Mestieri e Botteghe 2000 anni fa, Roma.

Bakker, J. T. 1994: Living and working with the Gods. Studies of evidence for private religion and his material environment in the city of Ostia (100-500 $A D)$, Dutch Monographs on Ancient History and Archaeology XII, Amsterdam.

Balil, A. 1972: "Casa y urbanismo en la España antigua. Casa familiar y vivienda colectiva en la España romana", Boletín del Seminario de Estudios de Arte y Arqueología 38, 55-131.

Barata, M. F. 1994: "A propósito do touro esculpido de Mirobriga", Vipasca 3, 73-77.

Boyce, G. K. 1937: Corpus of the Lararia of Pompeii, Memoirs of the American Academy in Rome 14, Roma.

Cau, M. A. y Chávez, M. E. 2003: el fenómeno urbano en Mallorca en época romana: los ejemplos de Pollentia y Palma", Mayurga 29, 27-49.

Chávez, Mª. E., Orfila, M. y Cau, M. A. 2010: "El Foro de Pollentia (Alcudia-Mallorca-España). Descubrimientos recientes", XVII International Congress of Classical Archaeology (Roma 2008), Trabalhos de Arqueologia e Antropologia I.

Clarke, J. R. 2003: Art in the lives of ordinary romans. Visual representation and non-elite viewers in Italy, 100 BC-AD 315, Berkeley-Los AngelesLondon.

Clarke, J. R. 2007: “Three uses of the pygmy and the aethiops at Pompeii: decorating, othering and warding off demonds", L. Bricault, M. J. Versluys y G. P. Meyboom (eds.) Nile into Tiber. Egipt in the roman world, III Int. Conference of Isis studies (Leiden 2005), Leiden-Boston, 155-169.

Combet-Farnoux, B. 1980: Mercure Romain. Le culte public de Mercure et la fonction mercantile a Rome de la republique archaique a l'epoque augusteene, Biblioteque des Ecoles Françaises d'Athenes et Rome 238, Roma.

D’Andria, F. 1970: "I Bronzi romani di Veleia, Parma e del territorio parmense", Contributi dell'Instituto di Archeologia, Serie III, vol. III, Milano, 3-141.

De Caro, S. 2000: Il Gabinetto Segreto del Museo Archeologico Nazionale di Napoli, Napoli.

Deonna, W. 1955: De Thélesphore au moine bourru. Dieux, génies et demons encapuchonnés, Collection Latomus 21, Berchem, Brussels.

Doengues, N. 2005: Pollentia. A roman colony on the Island of Mallorca, British Archaeological Reports, International Series 1404, Oxford.

Domingo, A., Druguet, G. y Mas, A. 2002: "De Sant Jaume de Guinyent a Sant Jaume d'Alcudia. Els cambis a la distribució del poblament concentrat en el terme de la parroquia de Sant Jaume de Guinyent (1230-1350)", II Jornades d'Estudis Locals d'Alcudia, Alcudia, 55-74.

Equip d'Excavacions de Pollentia 1994a: "Resultats dels treballs d'excavació a l'area central de la ciutat romana de Pollentia (Alcudia, Mallorca): Avanç preliminar", Pyrenae 25, 215-224.

Equip d’Excavacions de Pollentia 1994b: "Avanç dels resultats dels trebals d'excavacions a l'area central de la ciutat romana de Pollentia", La ciudad en el mundo romano, vol. 2, XIV Congreso Internacional de Arqueología Clásica, Tarragona, 140-142.

Eschebach, L. 1991: "Die Forumsthermen in Pompeji, Regio VII, Insula 5", Antike Welt 22.4, 257-287.

Faider-Feytmans, G. 1957: Récueil des Bronzes de Bavai, Suppl. Gallia 8, Paris.

Fröhlich, T. 1991: Lararien und Fassadenbilder in den vesuvstadten. Untersuchungen zur "volkstümlichen" pompejanischen Malerei, Mitteilungen des Deustchen archäologischen Instituts, Roman Abteilung 32, Mainz.

Galliazzo, V. 1979: Bronzi romani del Museo Civico di Treviso, Roma.

Gasparri, C. 1986: "Bacchus", Lexicon Iconographicum Mitologiae Classicae III, Zürich-München, 540-566.

Gassner, V. 1986: Die Kaufläden in Pompeii, Wien.

Girri, G. 1956: La Taberna nell quadro urbanistico e sociale di Ostia, Roma. 
Howe, T. P. 1954: "The origin and function of the Gorgon-head", American Journal of Archaeology 58, 209-221.

Johns, C. 1982: Sex or symbol?. Erotic images of Greece and Rome, London.

Kaufmann-Heinimann, A. 1998: Götter und Lararien aus Augusta Raurica. Herstellung, Fundzusammenhänge und sakrale Funktion figürlicher bronzen in einer römischen Stadt, Augst.

Kunckel, I. 1974: Die Römische Genius, Heidelberg.

Lequoy, M. C. y Guillot, M. 2004: Carte Archéologique de la Gaule. Rouen (72/6), Paris.

Llabrés, G. e Isasi, R. 1934: Excavaciones en los terrenos donde estuvo enclavada la ciudad romana de Pollentia (Baleares, Isla de Mallorca, Término municipal de Alcudia) Memoria de los trabajos practicados en 1930 y 1931, Memoria de la Junta Superior del Tesoro Artístico 131, Madrid.

MacMahon, A. 2003: The tabernae structures of roman Britain, British Archaeological Reports British Series 356, Oxford.

Manfrini, I. 1987: Bacchus dans les bronzes hellenistiques et romains. Les artisans et leur repertoire, Lausanne.

Marchetti, C. M. 2009-10: Il culto domestic ad Ercolano. Le evidenze archeologiche, tesis doctoral, Universita' del Salento.

Mastrobattista, E. 2009: “Abitare in pergula. Il sistema casa-bottega a Pompei”, A. Coralini (ed.) Vesuviana. Archeologie a confronto, Bologna, 509-517.

Mastrobattista, E. y Santoro, S. 2007: "Les maisons d'artisans-commerçants dans l'urbanime de Pompei", J. P. Petit y S. Santoro (coords.), De Pompei a Bliesbruck. Vivre en Europe romain, Paris, 113-120.

Merino, J. 1999: “Les excavacions arqueologiques de Gabriel Llabrés Quintana a Pol.lentia”, I Jornades d'Estudis Locals (Alcudia 1998), Alcudia, 39-50.

Monteix, N. 2010: Les lieux de Métier. Boutiques et Ateliers D'Herculanum, Biblioteque des Ecoles Françaises d'Athenes et Rome 34, Roma.

Morel, J. P. 1987: "La topographie de l'artisanat et du commerce dans la Rome antique", L'Vrbs. Espace urbain et historie. I siècle av. J.C. - III siècle ap. J.C., Ecole Française de Rome 98, Rome, 127-155.

Moreno, S. 2012: "La religión romana en Menorca: aproximación desde las fuentes iconográficas", Lucentum 21, 177-194.

Moreno, S. 2013: Contextualización de la escultura en la ciudad romana de Pollentia (Mallorca), tesis doctoral, Universidad de Granada.

Moreno, S., Orfila, M., Chávez, Mª E. y Cau, M. A. 2011: "Las áreas residenciales de Pollentia
(Alcudia, Mallorca) y sus materiales figurados en soportes plásticos", T. Nogales e I. Rodá (eds.), Roma y las provincias: modelo y difusión, XI Coloquio Internacional de Arte Romano Provincial (Mérida 2009), Hispania Antiqua, Serie Arqueológica 3, vol. II, Roma, 927-935.

Orfila, M. 2000: "Conclusions generals referents a l'estat de les investigacions arqueologiques en el forum de Pollentia”, M. Orfila (ed.), El forum de Pollentia. Memoria de les campanyes d'excavacions realitzades entre els anys $1996 i$ 1999, Alcudia, 131-159.

Orfila, M. 2007: "Una visión general de la ciudad romana de Pollentia. Época tardo-republicana y alto imperial", Mallorca romana, Asociación Amigos del castillo de San Carlos, Cuadernos de Historia no 3, Palma, 87-141.

Orfila, M. 2008: "La intervención de Q. Cecilio Metelo sobre las Baleares (123-121 a.C.). Condiciones previas y sus consecuencias", Pyrenae 39, 7-45.

Orfila, M., Arribas, A. y Cau, M. A. 1999: "El foro romano de Pollentia", Archivo Español de Arqueología 72, 99-118.

Orfila, M., Cau, M. A. y Chávez, Mª . E. 2005: "Últimos avances sobre la ciudad romana de Pollentia (Alcudia, Mallorca). 1996-2004”, M. L. Sánchez León y M. Barceló (coords.), L'Antiguitat clàssica i la seva pervivència a les illes Balears, XXIII Jornades d'Estudis Històrics Local (Palma 2004), Palma, 341-354.

Orfila, M., Chávez, Mª. E. \& Cau, M. A. 2006. "Pollentia and the cities of the Balearic Islands", L. Abad, S. Keay y S. Ramallo (eds.), Early roman towns in Hispania Tarraconensis, Journal of Roman Archaeology, Supplementary Series 62, 133-145.

Orr, D. 1978: "Roman domestic religion: the evidence of the hausehold Shrines", Aufstieg und Niedergang der romischen Welt. Geschichte und kultur roms im spiegel der neueren forschung, II, 16.2, Berlin-New York, 1557-1591.

Ortego, T. 1949: "Por tierras de Uxama. Hallazgos recientes de época romana", Archivo Español de Arqueología 22, 413-418.

Packer, J. 1971: The Insulae of imperial Ostia, Memoirs of the American Academy in Rome 31, Rome.

Papi, E. 2002: "La Turbia inpia: artigiani e commercianti del Foro Romano e dintorni (I secolo a.C. - 64 d.C.), Journal of Roman Studies 15.1, 45-62.

Papini, M. 2000: Palazzo Braschi. La collezione di sculture antichi, Bullettino della Comisione Archeologica Comunale di Roma, suppl. 7, Roma.

Perea, S. 1997: "El genio encapuchado de Pollentia en el MAN, y Telesforo, el dios médico de Pér- 
gamo", Boletín del Museo Arqueológico Nacional $15,129-134$.

Pérez Asensio, M. 2007: "Un edificio romano de tabernas en Lorca", Alberca 5, 67-79.

Pérez Ruiz, M. 2007-2008: "El culto en la casa romana", Anales de Prehistoria y Arqueología 23-24, 199-229.

Pérez Ruiz, M. 2014: Al amparo de los Lares. El culto doméstico en las provincias romanas Bética y Tarraconense, Anejos de Archivo Español de Arqueología LXVIII, Madrid.

Pirson, F. 1999: Mietwohnungen in Pompeji und Herculaneum. Untersuchungen zur Architektur zum Wohnen und zur Sozial- und Wirschaftgeschichte der Vesuvstädte, München.

Pozo, S. F. 1989: "Bronces romanos de Pollentia conservados en el MAN de Madrid", Boletín del Museo Arqueológico Nacional 7, no 1 - 2, 67-85.

Poulsen, E. 1977: "Probleme der Werkstattbestimmung gegossener römischer Figuralbornzen. Herstellungsmilieu und Materialstruktur", Acta Archaeologica 48, 1-60.

Purcell, N. 1994: "The city of Rome and the plebs urbanas in the later Republic", Cambridge Ancient History 9, 644-688.

Santoro, S., Mastrobattista, E. y Petit, J. P. 2011: "I sacra privata degli artigiani - commercianti: Qalche riflessione su due vici della Gallia Belgica a partire dall'evidenza pompeiana", F. Guedini y M. Bassani (eds.), Religionem Significare. Aspetti storico-religioso, structturall, iconografici e materiall del Sacra Privata, Rome, 181-204.
Santrot, J. 1993: "Le petit monde du laraire galloromain de Rezé (Loire-Atlantique)", Revue des Études Anciennes 95. 1-2, 265-295.

Sillieres, P. y Didierjean, F. 1977: "La onzieme campagne de fouilles de la Casa de Velázquez a Belo", Melanges de la Casa de Velázquez 13, 483-527.

Talvas, S. 2007: Recherches sur les figurines en terre cuite gallo-romaines en contexte archeologique, tesis doctoral, Universidad de Toulouse II- Le Mirail.

Tassignon, I. 1996: Iconographie et religion dionysiaques en Gaule Belgique et dans les deux Germanies, Bibliotheque de la faculté de Philosophie et Lettres de 1’Universite de Liège 265, Liège.

Vallori, B., Orfila, M. y Cau, M. A. 2011: "Las excavaciones de Gabriel Llabrés, Rafael Isasi y Juan Llabrés en la ciudad romana de Pollentia (Alcudia, Mallorca)", Archivo Español de Arqueología 84, 283-303.

Vallori, B. y Cau, M. A. (e.p.): "La Insula de tabernae del Foro de la ciudad romana de Pollentia (Mallorca): integración de disciplinas para propuesta de reconstrucción", Actas del XVIII Congreso Internacional de Arqueología Clásica (Mérida 2013).

Ventayol, P. 1927: Historia de Alcudia I, Palma de Mallorca.

Walde-Psener, E. 1983: I bronzetti fugurati antichi del Trentino, Trento.

Weddle, P. 2010: Touching the Gods: phisical interaction with cult statues in the roman world, tesis doctoral, Universidad de Durham (en web).

Zampieri, G. y Lavarone, B. 2000: Bronzi antichi del Museo Archeologico de Padova, Roma. 